\title{
Social Work Intervention against Illegal Child Adoption
}

\author{
N. S. Udechukwu ${ }^{a^{*}}$ \\ ${ }^{a}$ Department of Social Work, University of Nigeria, Nsukka, Nigeria. \\ Received 04 January 2019; Accepted 21 February 2019
}

\begin{abstract}
Children most times are vulnerable to abuse, unable to decide what happen to them and that is why intervention is necessary for the lives of children that are sold to unknown destinations in Nigeria. This study investigates social work intervention strategies against illegal child adoption in Enugu State, Nigeria. Mixed method design is used to authenticate data collected from questionnaire. Ministry of Gender Affairs (Welfare Unit Staff) Enugu and Welfare Office Nsukka were interviewed on the process of adoption and its efficacy. Two hundred questionnaires were shared to 200 respondents using availability sampling as method of their selection. The data were computed using the Statistical Package for Social Sciences (SPSS version 20). The findings show that majority $142(71 \%)$ of the respondents saw adoption as acceptable and government approved while $58(29 \%)$ said it stigmatizes and culturally disapproved. It also showed that majority $126(63 \%)$ go for illegal adoption while $74(37 \%)$ follow legal means. The reasons for illegal adoption - 88 (44\%) said cheaper avoiding bottlenecked procedures at the social welfare; 81 (40.5\%) said fear of being stigmatized by neighbours and 24 (12\%) ignorance of its consequences. Some $72(36 \%)$ said that some sell off their babies to avoid the stigma, shame, family/society's prosecutions, $85(42.5 \%)$ for economic reasons; $24(12 \%)$ is to do away with the baby and continue with life and $19(9.5 \%)$ supports all of the above reasons. Majority 157 (78.5\%) said no serious attention has been given by the government to stop baby selling due to corruption of the law enforcement agencies. The entire 200 (100\%) respondents agreed that social workers have many roles in preventing illegal adoption like working with the federal ministry of women or gender affairs to ensure proper child adoption and follow up after adoption to ensure the safety of the baby, since many baby buyers use them for rituals. These findings have obvious implications for social policies and future research on child welfare.
\end{abstract}

Keywords: Social Work Intervention; Baby Selling; Illegal Child Adoption; Stigma.

\section{Introduction}

Adoption places a child in a home where he/she enjoys all the rights and privileges of being part of that family. The National Assembly enacted the Child's Right Act in 2003. Part XII of the Act has provided comprehensive and uniform legislation on rights and welfare of children all over Nigeria. Reasons for adoption include childlessness; desire to replace a dead child, to get companion for an only child, to stabilize marriage, to legitimate an illegitimate child, to continue a particular line of descent especially males, to give a homeless child a permanent home, to relieve parents who are unable to take care of their child [1]. According to Eke et al. (2014) Nigerians see a child as social security to their parents. This makes every family to desire a child. Despite these genuine reasons for adoption, it has been discovered that some buy children for rituals while some trade them for money, depriving them their right to life [2].

Many who want to adopt go through illegal child adoption. They most times adopt through someone who sells or who helps the seller to sell. This illegal adoption has negative consequences. In Enugu State due to numerous sells of babies contrary to the laid down procedures guiding legal child adoption, social work intervention becomes paramount.

* Corresponding author: ngozi.ayigbo@unn.edu.ng

http://dx.doi.org/10.28991/SciMedJ-2019-0101-1

$>$ This is an open access article under the CC-BY license (https://creativecommons.org/licenses/by/4.0/).

(C) Authors retain all copyrights. 
Social work profession can use multi-dimensional approach to intervene against illegal child adoption in Nigeria, which is in line with its definition as a practice-based profession and a field that encourages change, social cohesion, empowerment and freedom of people. Central to social work are the principles of social justice, human rights, collective responsibility and respect for diversities. Social work employs people and structures to tackle life problems and improve their wellbeing. Hence, social work plays important role in preventing illegal child adoption which ranges from awareness campaign on consequences of illegal child adoption, advocacy/probation and influencing policy that can fight illegal child adoption among many others (IFSW, 2014) [3].

The increasing incidence of young, pregnant and helpless adolescent girls and poverty-stricken pregnant women being lured into giving away their babies after delivery for financial remuneration have labeled Nigerian society as one with the most dehumanizing form of child abuse, women sexual assault and trafficking. Charles et al. (2014) stated in their study that abject poverty is the primary motivation that is propelling mothers to give out their babies for money. Most people in baby factories producing children for sale are educationally challenged and were unable to complete secondary school education. In addition, girls or women that have failed in their petty businesses and needful of money to restart another businesses or start a vocation or to complete secondary school education also fall prey of baby selling. They also found that greed is one of the main motivating factors for the phenomenon of baby selling in Nigeria and some people purchase babies from baby factories in Nigeria for rituals while some of the buyers of the babies resell them for profit to mostly people living in the Diaspora and other baby buyers are women who are barren and have need of children. For Charles et al. (2014), it appears women living in the cities of Abuja, Lagos and the southsouth region of Nigeria are the major consumers of the numerous products of the baby factories situated in the southeastern part of the country [4]. UNESCO (2006) had earlier identified poverty, level of education, perversion of cultural traditions, and manipulation of religious rituals, harmful cultural and social realities as some of the root causes of baby selling in Nigeria [5]. Huntley (2013) emphasized that among the root causes of the phenomenon baby selling in Nigeria may be those that facilitate any other forms of human trafficking are such that have low levels of education, illiterate ones and people that lack information about human trafficking [6].

In Nigeria, apart from the adoption of children legitimately by Nigerians and some foreign nationals, cases of child abuse such as baby selling, the use of under aged children for street hawking, alms begging, and house help remains a challenge despite the domestication and adoption of the Child Right Law by several states in the Federal Republic of Nigeria [7, 8]. Though, the National Agency for the Prohibition of Traffic in Persons and other related matters (NAPTIP) was set up also by the Federal Government on the 8th of August, 2003 to address the scourge of trafficking in persons in Nigeria and its attendant human rights abuses in its entire ramifications much have not yet been achieved by the government due to corruption of the law enforcement agencies/officials (NAPTIP, 2013) [9].

According to Eke et al. (2014) [10], human trafficking is a major human rights violation, which United Nations in 2000 set up the Palermo protocols, tagged "Protocol to prevent, suppress, and punish trafficking in persons, especially women and children" (Palermo Protocol, 2013) [11]. The section 3(a) of this document defines child trafficking as the recruitment, transportation, transfer, harboring or receipt of persons by means of threat or the use of force or other means of coercion, abduction, fraud, deception, abuse of power or a position of vulnerability or the giving or receiving of payments or benefits to achieve the consent of a person having control over another person, for the purpose of exploitation. Exploitation here include prostitution or other forms of sexual exploitation, forced labor or services, slavery or practice similar to slavery, servitude or the removal of organs [11].

Also, Oladokun, et al (2009) showed that adoption which should be an alternative to infertility in South West Nigeria is not widely practiced due to some barriers like cultural practices, stigmatization, financial implications, and bottlenecks. They equally suggested measures to curb such barriers like advocacy, community mobilization and enactment of supportive laws that will protect all parties involved [12].

Eke et al. (2014) [10] discovered that there is emergence of middlemen who persuade prospective adoptive parents to avoid the procedural bottlenecks of adoption and adopt babies through unauthorized agents who keep pregnant girls illegally till their deliveries. The philanthropists, who discouraged young pregnant girls from aborting their babies, kept them until they deliver in a place started with genuine motive and later gave those babies for adoption. They affirmed that charlatans have now capitalized on that and turned it into a business thus, giving rise to baby factory. Example is Daughters of Divine Love (DDL), Eha Alumonah, Nsukka, which used to care for girls with unwanted pregnancy but along the line many things went wrong.

Furthermore, many adoptive parents complain of certain barriers to choosing adoption as management option to infertility. These barriers include fear of disloyalty by the child, future claim by the biological parents, lack of genetic linkage with the child and religious reasons [13]. There are other fears like genetically inherited traits. Counseling before the consummation of adoption will help clear these doubts. There are still misconceptions and wrong information on child adoption in our society. Fear of confidentiality, long waiting time, corruption, and procedural bottlenecks that involve the adoption process by staff of social welfare of the state makes prospective adoptive parents to patronize unregistered adoptive agents who contract the adoption for them at very exorbitant rates without proper pre-placement 
medical examination and no official records (Eke et al. 2014 [10]). Chukwu (2012) in his paper tagged adoption of children in Nigeria under the child's Right Act 2003 noted that social stigmatization is a major factor militating against adoption in Nigeria [1]. Hence, Aniebue and Aniebue (2008) recommended post-adoption care, especially for the developing countries where complex social and logistic factors work against legal adoption practice [14].

Many are confused on which one is a legal adoption and the illegal one. Ezugwu et al. (2002) reported that majority of infertile women in Enugu, South East Nigeria have heard of child adoption, but only a minority knew its real meaning, its legality, and what the processes are. Social workers should look into these problems and find solutions to them. Due to unguided illegal adoption some couples have adopted babies that have either hemoglobinopathy or pediatric retroviral infection without knowing. Some may adapt and manage the problem while some may abandon the baby in question. There are many risks that associate illegal child adoption for both the adoptive parents and the babies to be adopted. For instance, due process gives the adoptive parents irrevocable certificate of adoption but many have fallen victims of the biological parents coming to reclaim their child as a result of not following due process. Consequently, serious questions have been raised as to whether these teenage girls and the babies, who are being sold, are still the future leaders of this great country, Nigeria. It is therefore, on the account of the above ugly situations and its negative consequences that this study sought to investigate social work intervention strategies that can be used to fight these problems [15-17].

\subsection{Research Questions}

The following research questions were formulated to guide the study.

- What period in people's life do they seek to adopt a child?

- What are the reasons for illegal child adoption in Enugu State?

- What are the consequences of illegal child adoption?

- Are there meaningful interventions by the law enforcement agencies to stop illegal adoption?

- What are the strategies social workers can employ to prevent illegal adoption?

\subsection{Research Objectives}

The following objectives were formulated to guide the study.

- To find out the period people seek to adopt a child in Enugu State.

- To discover reasons for illegal child adoption in Enugu State.

- To determine the consequences of illegal child adoption in Enugu State.

- To know whether there are meaningful interventions by the law enforcement agencies to stop illegal adoption in Enugu State.

- To determine intervention strategies social workers can employ to prevent illegal adoption.

\section{Relevant Theories}

\subsection{Administrative Control Theory}

The administrative control theory was propounded by Useem \& Reisig 1999. Explain the situation whereby the authorities neglect their administrative responsibilities rather than their lack of awareness of it. The administrative control theory could be said to have argued that the cause of baby selling/illegal child adoption in Enugu State results from unstable, divided or otherwise weak management (Moser, 2012). One can clearly say, that people's engagement in the act of baby selling result from the neglect of duties of the various government agencies that fights against baby selling present in Nigeria. Agencies like, National agency for the prohibition of trafficking in persons and other related matters (NAPTIP), National emergency management agency (NEMA).

\subsection{Frustration Aggressive Theory}

Frustration aggressive theory otherwise known as the frustration aggressive displacement theory is a theory of aggression proposed by John Dolland, (1939), and further developed by Mile 1941 and also Leonard, Berkowiz in (1969). The theory developed by John Dolland and colleagues, says that frustration causes aggression, but when the sources of the frustration cannot be challenged, the aggression gets displaced, into innocent target. Most young girls, who get pregnant out of wedlock, are faced with heavy stereotype in the society and even in their various homes. Also they are seen as people who have done the undoable, as such are not given proper respect they deserve in their homes and the society at large thereby resulting to the aggression on the part of the young girls, but seen they cannot confront the source of the aggression they tend to displaced such aggression on the innocent child, which most times resulted in them selling the baby so as to get their peace, which gives rise to illegal adoption. 


\subsection{Theoretical Framework}

The administration control theory forms the theoretical framework of this research. The theory was put forwards by Useem and Reisig in 1999. The theory explains the situation whereby the authorities neglect their administrative responsibility, rather than their lack of awareness of it. Using this theory to explain the fact that people tend to engage in the act of baby selling/illegal child adoption because the authorities responsible for preventing it are not effective in discharging their duties hence people tends to engage in baby selling knowing very well that the authorities responsible for punishing the act is not effective. One could say that, government agencies such as National Agency for the prohibition of trafficking of persons and other related matters (NAPTIP) and other security agencies are not getting to the grassroot, where the real thing happen.

\section{Materials and Methods}

Mixed method design is used to authenticate data collected from questionnaire. The research adopted a cross sectional survey design. Cross sectional survey is designed to enable researcher examine a population by taking a cross section of it at one point in time. Similarly, Trochim (2006) maintained that cross-sectional survey research study is a descriptive study; it is a type of observational study that involves data collection from a population, or a representative subset, at one specific point in time with the aim of providing data on the entire population under study [18].

Enugu state was used as the study area and availability sampling was used to select 200 respondents, who answered the researcher's questions on illegal child adoption. In addition, qualitative data was collected from Ministry of Gender Affairs Enugu (Welfare Unit) and Social Welfare Staff, Nsukka. Information was also collected from NAPTIP officers. This was meant to complement the data from the questionnaire items.

\section{Results}

The following tables show the results of the research.

Table 1. The demographic characteristics of the respondents

\begin{tabular}{|c|c|c|c|c|c|}
\hline Age & Frequency & Percent $(\%)$ & Marital Status & Frequency & $\begin{array}{c}\text { Percent } \\
(\%)\end{array}$ \\
\hline $14-23$ years & 104 & 52.0 & Single & 146 & 73.0 \\
\hline $24-33$ years & 53 & 26.5 & Married & 53 & 26.5 \\
\hline $34-43$ years & 28 & 14.0 & Separated/Divorced & 1 & 0.5 \\
\hline $44-53$ years & 15 & 7.5 & Total & 200 & 100.0 \\
\hline Total & 200 & 100.0 & & & \\
\hline Sex & Frequency & Percent & Educational Qualification & Frequency & Percent \\
\hline Male & 100 & 50.0 & No formal education & 7 & 3.5 \\
\hline Female & 100 & 50.0 & FSLC & 4 & 2.0 \\
\hline Total & 200 & 100.0 & GCE/WASC & 68 & 34.0 \\
\hline Occupation & Frequency & Percent & OND/NCE & 39 & 19.5 \\
\hline Student & 149 & 74.5 & B.Sc & 67 & 33.5 \\
\hline Unemployed & 4 & 2.0 & M.Sc./Ph.D & 15 & 7.5 \\
\hline Self employed & 5 & 2.5 & Total & 200 & 100.0 \\
\hline Civil Servant & 40 & 20.0 & & & \\
\hline Others specify & 2 & 1.0 & & & \\
\hline \multirow[t]{2}{*}{ Total } & 200 & 100.0 & & & \\
\hline & & & Income Level & Frequency & Percent \\
\hline Religion & Frequency & Percent & $\mathrm{N} 1,000.00-\mathrm{N} 20,000.00$ & 54 & 27.0 \\
\hline Christianity & 193 & 96.5 & $\mathrm{~N} 21,000.00$ - N40,000.00 & 25 & 12.5 \\
\hline Islam & 2 & 1.0 & $\mathrm{~N} 41,000.00$ - N60,000.00 & 8 & 4.0 \\
\hline ATR & 2 & 1.0 & N61,000.00 and above & 31 & 15.5 \\
\hline Others specify & 3 & 1.5 & No Income & 82 & 41.0 \\
\hline Total & 200 & 100.0 & Total & 200 & 100.0 \\
\hline
\end{tabular}

Table 1 shows the demographic characteristics of the respondents by age, sex, marital status, occupation, educational qualification, religious affiliation and income level. The table shows that $104(52 \%)$ of the respondents are still within the teen age, $146(73 \%)$ are still single, there are equal representatives of both sex $100 \%$ (50\% males and $50 \%$ female), 
majority are students 149 (74.5\%), the respondents are mainly Christians 193 (96.5\%) and lastly, their income level shows that majority of the respondents are struggling financially - $82(41 \%)$, which is the highest had no income at all, followed by $54(27 \%)$ that their income level fell within N1,000.00 and N20,000.00 while only 31 (15\%) of the respondents could earn N61,000.00 and above. The poverty level of the study area is very high and needed urgent attention.

Table 2. People's view about child adoption in Enugu State

\begin{tabular}{lcc}
\hline What are your views about child adoption in Enugu State? & Frequency & Percent (\%) \\
\hline It is acceptable and government approved & 142 & 71.0 \\
It stigmatizes people and Culturally disapproved & 58 & 29.0 \\
\hline Total & $\mathbf{2 0 0}$ & $\mathbf{1 0 0 . 0}$ \\
\hline
\end{tabular}

Table 2 shows that $142(71 \%)$ of the respondents accepted child adoption while $58(29 \%)$ said it stigmatizes people and is culturally disapproved.

Table 3. When People Adopt

\begin{tabular}{lcc}
\hline When do people adopt? & Frequency & Percent (\%) \\
\hline At the discovery of inability to give birth & 160 & 80.0 \\
People do not like to adopt at all & 22 & 11.0 \\
When they are old enough & 18 & 9.0 \\
\hline Total & $\mathbf{2 0 0}$ & $\mathbf{1 0 0 . 0}$ \\
\hline
\end{tabular}

Table 3 shows that $160(80 \%)$ will adopt at the discovery of their inability to give birth; $22(11 \%)$ said that people do not like adoption at all while the remaining $18(9 \%)$ said people adopt when they are already old living the child to suffer, since some of them will no longer be strong in training and providing their basic needs.

Table 4. Reasons some mothers sell off their babies

\begin{tabular}{lcc}
\hline Why do mothers sell off their babies? & Frequency & Percent (\%) \\
\hline To avoid shame, stigma and family/society's prosecution & 72 & 36.0 \\
Poverty or for economic reasons & 85 & 42.5 \\
To do away with the baby and continue with life e.g. education & 24 & 12.0 \\
Others specify and all of the above & 19 & 9.5 \\
\hline Total & $\mathbf{2 0 0}$ & $\mathbf{1 0 0 . 0}$ \\
\hline
\end{tabular}

Table 4 shows the reasons some mothers sell off their babies. Seventy-two (36\%) said shame, stigma and family/society's prosecution in case of teenage pregnancy; 85 (42.5\%) talked about poverty (i.e. for economic reasons); $24(12 \%)$ said to do away with the baby and continue with life example their education. Many teenagers do not want their future partner to know they have delivered before while the remaining $19(9.5 \%)$ supports the whole options as reasons for sale of babies by their mothers.

Table 5. Means of illegal child adoption in Enugu State

\begin{tabular}{lcc}
\hline If yes in question 10, how did they do the adoption? & Frequency & Percent (\%) \\
\hline Through Legal means with the help of a lawyer/with the help of social workers & 37.0 & 74 \\
Illegal means like doctors/nurses that run hospitals/maternity homes and through girls that want to sell their babies & 126 & 63.0 \\
\hline Total & $\mathbf{1 0 0 . 0}$ \\
\hline
\end{tabular}

Table 5 shows that the majority $126(63 \%)$ of the respondents said that the people they know that did adoption was through illegal means like going through doctors and nurses that run hospitals/maternity homes and contracting with girls and women that want to sell of their babies while 74 (37\%) said through legal means by meeting a lawyer or social worker who took them through the due process of child adoption with the help of social welfare unit in the state. 
Table 6. The reasons for illegal child adoption in Enugu State

What can lead a couple to buy a baby illegally instead of going through government approved process of adoption? Frequency Percent

\begin{tabular}{lcc}
\hline It is cheaper through illegal means & 88 & 44.0 \\
Fear of being stigmatized by neighbours & 81 & 40.5 \\
Ignorance of its consequences & 31 & 15.5 \\
\hline Total & $\mathbf{2 0 0}$ & $\mathbf{1 0 0 . 0}$ \\
\hline
\end{tabular}

Table 6 shows that majority 88(44\%) of the respondents opined that the reason for illegal adoption is that it is cheaper like delay from staff in social welfare department; followed by $81(40.5 \%)$ that said it is because of fear of being stigmatized by neighbours and $31(15.5 \%)$ said ignorance of its consequences.

Table 7. The consequences of illegal child adoption in Enugu State

\begin{tabular}{lcc}
\hline What do you think can be the consequences of illegal adoption? & Frequency & $\begin{array}{c}\text { Percent } \\
(\%)\end{array}$ \\
\hline The baby may be bought by child traffickers or ritualists that may lead to the death of the baby & 122 & 61.0 \\
Retarded growth as a result of not taking breast milk and lack of motherly care, which can cause & 32 & 16.0 \\
emotional imbalance & 13 & 6.5 \\
Inner emptiness of not being able to give birth & 17 & 8.5 \\
$\begin{array}{l}\text { For women that inflate their stomach pretending to be pregnant, they might end up contacting } \\
\text { disease or womb cancer }\end{array}$ & 16 & 8.0 \\
Others specify & $\mathbf{2 0 0}$ & $\mathbf{1 0 0 . 0}$ \\
\hline Total
\end{tabular}

Table 7 shows that majority $122(61 \%)$ of the respondents agreed that most illegal child adoption lead to death since many buyers are ritualists; followed by $32(16 \%)$ of the respondents that said retarded growth as a result of not taking breast milk and emotional imbalance due to lack of motherly love and care.

Table 8. Respondents' opinion of whether government is doing anything to prevent illegal child adoption in Enugu State

\begin{tabular}{|c|c|c|}
\hline What are the measures applied by the government to discourage illegal adoption in Enugu State? & Frequency & Percent $(\%)$ \\
\hline Nothing because corruption by the law enforcement agent will not allow them & 157 & 78.5 \\
\hline Yes, like confiscation of baby factories and rescuing of victims of such illegal adoption & 43 & 21.5 \\
\hline Awareness programmes using social media that exposes the consequences of illegal adoption & 0 & 0.0 \\
\hline Legalization of social work profession in Nigeria & 0 & 0.0 \\
\hline Employment of social workers as heads of social welfare offices in the states & 0 & 0.0 \\
\hline Employment of social workers in hospitals to monitor proper registration of every baby delivered & 0 & 0.0 \\
\hline Total & 200 & 100.0 \\
\hline
\end{tabular}

Table 8 shows that majority $157(78.5 \%)$ of the respondents are of the view that the government is not doing anything to stop illegal child adoption in Enugu State. Forty three $(21.5 \%)$ said yes but no record of punishment given to those law breakers.

Table 9. Suggested strategies that can be used to prevent illegal adoption in Enugu State

\begin{tabular}{lcc}
\hline What can the government do to prevent illegal child adoption in Enugu State? & Frequency & Percent (\%) \\
\hline Empower the legal unit to prosecute any defaulter & 58 & 29.0 \\
Legalize social work profession to enable them take up their advocacy job proper & 55 & 8.0 \\
Empower youths and educate them on the implications of illegal adoption & 37 & 27.5 \\
Making sure every maternity home or hospital registers babies delivered in those places & 34 & 18.5 \\
Others specify and all of the above responses & $\mathbf{2 0 0}$ & $\mathbf{1 0 0 . 0}$ \\
\hline Total &
\end{tabular}


The Table 9 shows that the entire respondents are of the opinion that the government should implement the child right act that says that the child has right to live and be cared for by affirming the four options raised in the table. The government should legalize social work profession in Nigeria to enable them practice.

Table 10. Social work interventive roles in preventing illegal child adoption

\begin{tabular}{lcc} 
What are the roles social workers can play to ensure legal adoption of children in Enugu State? & Frequency & Percent (\%) \\
\hline Education of the masses on the consequences of illegal adoption & 109 & 54.5 \\
Work with the welfare office to ensure the status of every adopting parents & 24 & 17 \\
Follow up in their houses to ensure the safety of the baby from time to time & 24 & 8.5 \\
Reporting any trace of abuse on the baby or any sign of baby trafficking & 26 & 13.0 \\
Others specify and all of the above & $\mathbf{2 0 0}$ & $\mathbf{1 0 0 . 0}$ \\
\hline Total & & 2.0 \\
\hline
\end{tabular}

Table 10 shows the roles social workers can play in preventing illegal child adoption in Enugu State and any part of the world. The $200(100 \%)$ of the respondents agreed that social workers have one role or the other to play to ensure the safety of a child. Majority 109 (54.5\%) talked about education of the masses on the consequences of illegal child adoption. Twenty four (12\%) said that social workers are to work with welfare office to ensure the status of every adopting parents to be sure that they will be able to take care of the baby and that they are not child traffickers among others as shown in the table above.

\subsection{Results from Qualitative Findings}

Interview with the agencies responsible for adoption and child welfare were held. They are the Social Welfare Staff, Nsukka, Ministry of Gender Affairs, Enugu (Welfare unit staff) and NAPTIP staff. The researcher asked the following questions.

- What are the roles of social welfare in child adoption?

- What do you do to prevent illegal child adoption?

- What are the procedures for child adoption?

- Are there records on adoption cases fully concluded?

- Do you know any place where illegal adoption takes place?

In response to the above questions, the social welfare staff said that they play the role of a probation officer during adoption. When an abandoned child is discovered, the person should first of all report to the police for proper investigation. After that, the child is registered in the welfare office; the welfare officer will place the child on foster care for 3 months with the person who wants to adopt the child. During the period of 3 months, social welfare officer will do investigation on reasons for choosing to adopt, your background, situation and medical state of both the child and the adoptive parents and also to know whether the rightful owner of the child will show up. If the right parents did not show up after 3 months, they will proceed to the court. The adoption ruling is done inside the chamber and not in the open court. After the ruling, an irrevocable certificate of adoption will be issued to the parent and the child becomes his forever. The adoptive parent cannot come back to say, I do not want the child again likewise sudden surfacing of the biological parent cannot reverse the verdict. This solves the problem of reclaiming of babies bought through illegal means. As discovered during the course of this research, it is possible to sell a baby illegally and return after a long period of time to reclaim the baby through legal means. This is another reason; people should not follow illegal adoption to avoid waste of money, love, time and energy.

The welfare officer noted that it is the duty of the police to stop illegal adoption through investigation, stating that they only get involved in training or educating people that come for adoption. She further stated that it is necessary for the Social Welfare Office to create awareness on, or campaign against illegal child adoption and its attendant consequences, however this has not been done.

NAPTIP has affirmed that they are working with the government to protect people's rights, and they have gone on air to talk about implications of illegal adoption and trafficking. Many traffickers and operators of illegal adoption centers have been caught and most have been prosecuted. A constrain to this prosecution has been Godfathers and undue influence from top ranking individuals.

However, the law requires that evidences of exploitation have to be made before prosecution, which is always difficult to provide. This supports my finding that says that the government does nothing to prosecute the offenders due to corruption of the law enforcement agencies. The administrative control theory is upheld as bases to this research. 
The Social Welfare office at Nsukka said that they use to complete the process of adoption but for now they no longer do that, being that cases of adoption are referred to the ministry of Gender Affairs, Enugu which is solely responsible for adoption now in Enugu State. The office recorded 5 children placed on foster homes last year 2017 but adoption has not been completed on them. This year 2018 no child has been fostered. The ministry of gender affairs does that through their welfare unit. As at the time the researcher went there, there are some adoption application on process but have not been completed. This shows that many go through illegal means not minding the consequences because adoptions happen often in Enugu State.

The report showed that some of the known adoption centers are closed due to government intervention like Daughters of Divine Love, Eha Alumonah, Nsukka. According to the officer in charge of Nsukka Welfare they started with good motive helping to keep teenagers that got pregnant to avoid public shame but were later abused, babies were sold indiscriminately and government started probing them and it closed. In Enugu, there is Mother of Christ Motherless Babies Home where children to be adopted can be found and they work with the National Council of Women Organisation in propagating legal adoption. It was reported that many abandoned children can as well be sold out by so called legal means (Anonymous, 2018). In Nsukka, there is Motherless Babies Home owned by group of women organization registered with Social Welfare but are not taking care of abandoned children. It is stated emphatically that many donations are going to them but the truth is that every child there has someone catering for him/her. Take an abandoned baby there; they will reject the baby unless you will be providing for the baby despite the huge donations coming to them. This means they share the donations among themselves.

The researcher discovered that there are secret baby selling going on in Enugu State but many are afraid to report the case. The government cannot prosecute any victim without evidence and witness. People are not willing to expose or give useful information and evidence to the relevant offices as to the operations of these illegal adoption centers or the activities of traffickers, due to the fear of assassination. What can a social worker do in this situation? As a profession, we respect and uphold the principle of confidentiality as we practice.

\section{Discussion}

A total of 200 (100 male and 100 female) respondents were used for the study. The qualitative data was gotten from Ministry of Gender Affairs, Enugu, Social welfare, Nsukka and NAPTIP. The age range of respondents was from 14 to 53 years. Majority 104 (52\%) of my respondents fall within the age range $14-23$ years and that was why many of the respondents $142(71 \%)$ saw child adoption as something acceptable and government approved; majority 160 (80\%) agreed that people adopt at the discovery of inability to give birth, which out of $160(100 \%), 124(77.5 \%)$ fall within the age range 14 - 33 years (young people) giving hope of an improved attitude towards adoption in Enugu State. However, it contradicts the real practice on ground, which is partial acceptance of child adoption due to cultural inclinations by the people. The interview session with the staff of Nsukka Welfare shows that it is only 5 children have been recorded as being placed in foster homes last year 2017 and none has been adopted or fostered for this year 2018. The federal ministry of gender affairs handles adoption but few complete the requirements for adoption. The results showed that 58 (29\%) see it as culturally disapproved and that it stigmatize the parent and baby adopted. This supports Oladokun et al. (2009) [12] that discovered that stigma and culture serves as barriers to legal adoption. Only 6 (3\%) said that people do not like adopting at all while $18(9 \%)$ said that couples adopt when they are already old thereby exposing the child to poverty, since the adopting parents are no longer strong to carter for the baby [19].

Majority of them $138(69 \%)$ have seen babies that have been adopted while the remaining $62(31 \%)$ have not seen adopted babies before now. Seventy four (37\%) of respondents said that those they know adopted through legal means while 126 (63\%) said the adoptions were illegal like contracting with doctors/nurses that run hospitals/maternity homes and by contracting with girls that want to sell their babies. This is in line with Eke et al. (2014) [10] discovery that there are emergences of middlemen who persuade prospective adoptive parents to avoid the procedural bottlenecks of adoption and adopt babies through unauthorized agents who keep pregnant girls illegally till their deliveries. Seventy two $(36 \%)$ agreed that reasons for selling off ones baby is to avoid shame, stigma and family/society's prosecution; 85 $(42.5 \%)$ admitted that it is for economic reasons invariably poverty, which is in line with the researcher's discovery of a woman that has many children who later gave birth but sold that one in other to use the money to keep other children; $24(12 \%)$ sell off their babies in other to continue with their life like education while 19 (9.5) gave multiple answers saying that it can be for both to prevent shame, stigma, fear of family prosecution and to continue with life. This also concurs with the findings of Akwara and Andeshi (2014) that stated that abject poverty is the primary motivation that is propelling mothers to give out their babies for money. It also rimes with the researcher's findings that some students, even in University of Nigeria, Nsukka get pregnant and sell them off without the knowledge of their parents, use the money to further the course of their education and life in general. One student wanted to abort and ran into a doctor that encouraged her, paid for her antenatal and after she sold the baby for N1,000,000.00; 200,000 was given to the sisters that assisted her in selling the baby and 200,000.00 to the doctor that assisted her during the pregnancy but the doctor refused the money and said, 'I only wanted to save your life and that of the baby'. 
In addition, $88(44 \%)$ said that couples buy baby illegally because it is cheaper, avoiding bottlenecked process from social welfare; $81(40.5 \%)$ said because of fear of being stigmatized by neighbours, $24(12 \%)$ said that they are ignorance of its consequences while 7 (3.5\%) chose the whole options as the reasons. This is contrary to the opinion of the staff of the Nsukka welfare that says that the illegal one is costlier, which supports Eke et al. (2014) [10] opinion that state that fear of confidentiality, long waiting time, corruption, and procedural bottlenecks that involve the adoption process by staff of social welfare of the state makes prospective adoptive parents to patronize unregistered adoptive agents who contract the adoption for them at very exorbitant rates without proper pre-placement on medical examination and without official records. The result shows that $122(61 \%)$ acknowledge that babies who are victims of illegal child adoption end up in the hands of ritualists that lead to death. Followed by $32(16 \%)$ that said retarded growth as a result of not taking breast milk and lack of motherly care, which can cause emotional imbalance; $13(6.5 \%)$ talked about inner emptiness of not being able to give birth; $17(8.5 \%)$ talked in regard to the health of women that inflate their stomach pretending to be pregnant, that they might end up contacting disease or womb cancer while $16(8 \%)$ agreed with the four reasons already mentioned.

Most of the respondents $152(76 \%)$ noted that there is no meaningful thing the government does to stop illegal child adoption, $1(0.5 \%)$ said that they do not know while the remaining 47 (23.5\%) said they are doing something. Majority $157(78.5 \%)$ of the respondents are of the view that the government is not doing anything to stop illegal child adoption in Enugu State because of corruption of the law enforcement agencies. Forty three $(21.5 \%)$ said yes but no much records of punishment given to those law breakers. This contradicts the opinion of the NAPTIP that says that much are being done to curb illegal adoption in Enugu State. This makes administrative control theory by Useem and Reisig in 1999 that explains lack of implementation of policies guiding adoption by government officials suitable for this study.

The $200(100 \%)$ of the respondents agreed that social workers have one role or the other to play to ensure the safety of a child. Majority 109 (54.5\%) talked about education of the masses on the consequences of illegal child adoption. Twenty four $(12 \%)$ said that social workers are to work with welfare office to ensure the status of every adopting parents to be sure that they will be able to take care of the baby and that they are not child traffickers or ritualists. Seventeen $(8.5 \%)$ talked about follow up in their houses to ensure the safety of the baby from time to time after having gotten the irrevocable certificate of adoption. The findings show that most of the officials in social welfare agencies are not social workers and if social workers will head those units they will do better jobs. This advocates the fact that there is need to legalize social work profession in Nigeria, which will empower social workers to do their work of protections of people's rights and advocacy among others. This is contrary to the findings from Nsukka welfare office that says that there is nothing like follow up after adoption, since irrevocable certificate of adoption has been issued to the adoptive parents and no outdoor programmes like seminars where awareness will be created that will reduce illegal child adoption. Twenty four (12\%) of the respondents are of the view that social workers should report any trace of abuse on the baby or any sign of baby trafficking.

\section{Conclusion and Recommendation}

Most people are away of legal adoption but few go through it. Stigma, shame and economic factors are still strong reasons for baby selling and illegal child adoption. Couples still feel inner emptiness of inability to produce a baby and that leads them to do so many hiding and pretention to confuse the society. Social workers should take note of all these emotional issues, cultural barriers and try to help people come out of them by making adoption acceptable and attractive in the society. What matters most are parents being able to inculcate good values in their children whether adopted or biologically acquired. Success must have a successor and that should be the target. Trying to please people around and thereby hurting ones' self should be fought against.

Government should legalize social work profession in Nigeria for proper licensing. This will give social work profession recognized mandate to operate in the full capacity of their professional strength to prevent illegal child adoption in Enugu State and Nigeria as a whole. Moreover, there should be continued advocacy and public enlightenment campaigns by both social workers and governmental agencies that protect the rights of the people to ensure that legal adoption process is followed. Proper counselling should be given to adoptive parents and follow up should be made to their houses to ensure safety of the adoptee. The situation of this country is where many good policies are on paper but practical implementation becomes a problem. This has to be addressed. All stakeholders should work hard to reduce or prevent this problem of illegal adoption and make sure the rights of those adoptees are respected.

Serious awareness programmes should be made on the consequences of illegal child adoption and baby selling. This will bring all concerned to the level of knowing the implications and be able to make right decisions. Government should also make sure that every maternity and hospital registers every birth that took place in those places. In addition, social workers should be employed to monitor births taking place in those places, even work with community leaders to monitor births in people's houses. This will help to reduce indiscriminate baby selling by some hungry women in the rural areas.

The agency in-charge of adoption should make sure that the adoption applicants must go through thorough home 
study, which should include the details of the applicants' physical and mental health, family status, financial condition, personal repute, home environment, ability to give love and care to the child, motivation and any special reasons related to the welfare and interest of the child, and other matters pertinent to child adoption (https://www.motherschoice.org/en/what-we-do/for-families/adopt-a-child/) [10]. The adoptee should also be examined medically to ensure that the baby is healthy before adoption process is consummated.

Our values system has to be revisited for proper orientations of people's mindset that will enable us uphold change and maintain good values and not being greedy or corrupt.

\section{Declaration of Competing Interest}

The authors declare that they have no known competing financial interests or personal relationships that could have appeared to influence the work reported in this paper.

\section{References}

[1] Chukwu, L. O. (2012). Adoption of children in Nigeria under the Child's Rights Act 2003. Available online: http://www.Law.2.byu.edu/chukwu.pdf (accessed on 1 May 2018).

[2] Eke, CB, HA Obu, JM Chinawa, GN Adimora, and IE Obi. "Perception of Child Adoption Among Parents/care-Givers of Children Attending Pediatric Outpatients' Clinics in Enugu, South East, Nigeria." Nigerian Journal of Clinical Practice 17, no. 2 (2014): 188. doi:10.4103/1119-3077.127549.

[3] IFSW, I. (2014). Global definition of the social work profession. Available online: http://ifsw, org/get-involved/global-definitionof-social-work (accessed on 14 February 2016).

[4] Charles, A., Akwara, A. F., \& Andeshi, C. A. (2014). Dialectics of the incubation of 'baby factories' in Nigeria. International Journal of Peace and Conflict Studies, 2(1), 82-90.

[5] UNESCO. (2016). Human trafficking in Nigeria: root causes and recommendations. Policy Paper No 14.2 (E). Paris: Available online: http://unesdoc.unesco.org/image s/0014/001478/147844E.pdf (accessed on 19 February 2017).

[6] Huntley, S. S. (2013). The Phenomenon of" baby Factories" in Nigeria as a New Trend in Human Trafficking. International Crimes Database.

[7] Federal Republic of Nigeria (2013). National policy on education (6th ed). Lagos: NERDC Press.

[8] Business Day Online (2013). Available online: http://businessdayonline.com/NG?index.php/city-file/city-file/49791-groupfaults-rising-trend-in-child (accessed on 22 March 2018).

[9] National Agency for the Prohibition of Traffic in Persons and other related matters (NAPTIP) (2013). About us. Available online: http://www.naptip.gov.ng/aboutus.html (accessed on 11 May 2018).

[10] Eke, C. B., Obu, H. A., Chinawa, J. M., Adimora, G. N., \& Obi, I. E. (2014). Perception of child adoption among parents/caregivers of children attending pediatric outpatients' clinics in Enugu, South East, Nigeria. Nigerian journal of clinical practice, 17(2), 188-195.

[11] Palermo Protocol (2013). United Nations protocol to prevent, suppress, and punish trafficking in persons, especially women and children, 2000. Available online: http://www.unodc.org/documents/treaties/UNTOC/Publications/ TOC\%2520Convention/TOCebook-e.pd (accessed on 27 June 2018).

[12] Oladokun, A., Oladokun, R., Morhason-Bello, I., Arulogun, O., Bamgboye, A., Adewole, I., \& Ojengbede, O. (2009). O708 Attitude of infertile women to child adoption in Nigeria. International Journal of Gynecology \& Obstetrics, 107, S296-S296. doi:10.1016/s0020-7292(09)61081-x.

[13] Van Den Akker, O. B. A. (2001). Adoption in the age of reproductive technology. Journal of Reproductive and Infant Psychology, 19(2), 147-159. doi:10.1080/02646830125231.

[14] Aniebue, P. N. (2008). Adoption practices in Enugu, Nigeria. Nigerian journal of clinical practice, 11(1), 5-8.

[15] Ezugwu, F. O., Obi, S. N., \& Onah, H. E. (2002). The knowledge, attitude and practice of child adoption among infertile Nigerian women. Journal of Obstetrics and Gynaecology, 22(2), 211-216. doi:10.1080/01443610120113463.

[16] Omosun, A. O., \& Kofoworola, O. (2011). Knowledge, attitude and practice towards child adoption amongst women attending infertility clinics in Lagos State, Nigeria. African Journal of Primary Health Care \& Family Medicine, 3(1). doi:10.4102/phcfm.v3i1.259.

[17] Nwobodo, E. I., \& Isah, Y. A. (2011). Knowledge, attitude and practice of child adoption among infertile female patients in Sokoto north-west Nigeria. The Nigerian postgraduate medical journal, 18(4), 272-275. 
[18] Trochim, W. M. (2006). The research methods knowledge base 2nd Edition. Retrieved from.

[19] Federal Ministry of Women Affairs (2005). Child's Right Act: Simplified Version; 2005. p. 1-16. 